\title{
Sustainability: The Water and Energy Problem, and the Natural Design Solution
}

\author{
A D R I A N B E J A N \\ Duke University, Durham, North Carolina 27708-0300, USA. \\ E-mail: abejan@duke.edu
}

People like to say that energy and water are two problems, two vital commodities in short supply. Here I draw attention to the emerging literature and physics principle (constructal law) that provide the scientific foundation for sustainability. I show that the sustainability need is about flow: the flow of energy and the flow of water through the inhabited space. All the flows needed for human life (transportation, heating, cooling, water) are driven by the purposeful consumption of fuels. This is why the wealth of a country (the GDP) is directly proportional to the annual consumption of fuel in that country. This hierarchical organization happens; it is natural and efficient. Sustainability is the one-word need that covers all the specific needs. Sustainability comes from greater freedom in changing the organization - the flow architecture - that sustains life. Greater freedom to change the design (from water and power to laws and government) leads to greater flow, wealth, life and staying power, i.e. sustainability.

The energy and water 'problems' are commonly described in terms with which nobody could possibly disagree. Here are two examples:

- 'Life would not exist without water'. This is true but incomplete. Life would not exist without the flow of water through us and our space.

- 'Energy and water are two vital commodities'. This is not accurate either. Vital yes, commodities no. There is plenty of water in a swamp, and plenty of solar energy falling on the Sahara. Neither is precious because neither is flowing through the space inhabited by human life.

Here I draw attention to an emerging literature that recognizes energy and water not as commodities, but as flows that sustain and define human life. ${ }^{1-5}$ Water and energy are not two flows but one flow, which is responsible for all the aspects of life: transportation, heating, cooling, fresh water, and so on.

At bottom, this single flow represents the movement of humanity on the globe. Movement is life. The movement is driven by power derived from fuels of all kinds. 
It is why the annual economic activity of a country (the GDP) is proportional to its fuel consumption (Figure 1). Human movement is synonymous with wealth.

Humanity is just one of an immense number of biological water-flow systems on earth. It is the most potent of them all, in fact, the more advanced we become the more water we move on the landscape. We change the landscape to such degrees that we are witnessing our own geological age on Earth.

Like all the world problems, the water problem is not distributed evenly on the globe. There are water stressed regions, and there are regions of plenty. Why then are North America and Europe not water stressed? These are not regions that break rainfall records. The Congo is. North America and Europe are regions with agriculture; in fact they serve as bread baskets for the whole world. Why is it that the water problem is distributed so unevenly?

The clue is that the unevenness of the water problem matches the hierarchy of human movement on the globe (Figure 2). Furthermore, the unevenness of human movement matches the uneven distribution of wealth. Also note the agreement between Figure 2 and Figure 1.

'Advanced' means movement (water flow, science, technology, etc.), and this is where the physics of life comes in. Advancement means ultimately one thing: moving greater currents on the landscape, more easily, farther, and longer lasting.

All the earth's flows are driven by the heat engine that operates between heating from the sun and heat rejection to the cold sky. ${ }^{8}$ The global heat engine produces work, but there is no external system that can receive this work. Instead, the work is dissipated entirely into heat on earth. The net effect of the flow of heat from hot to

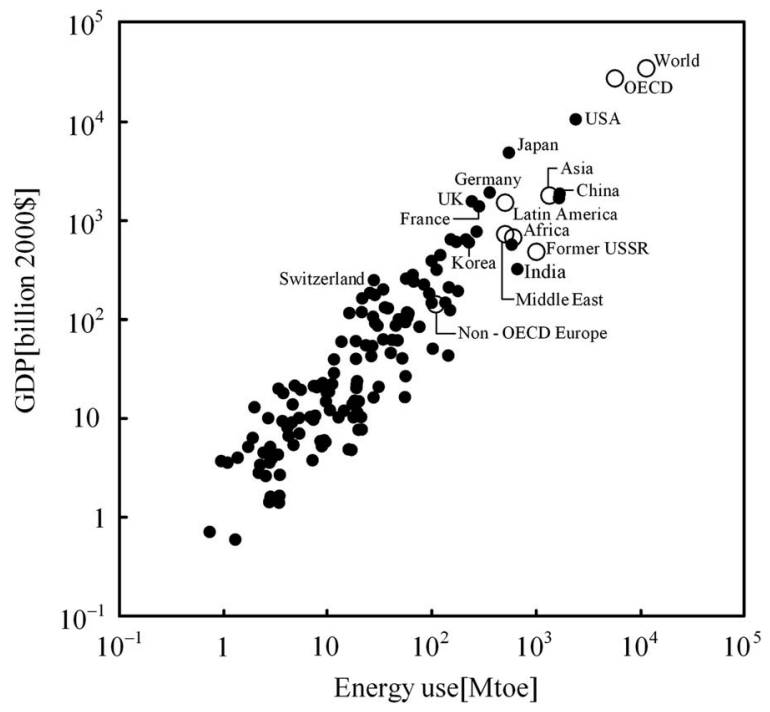

Figure 1. Wealth is movement. Economic activity means fuel that is being burned for human use: the GDP (Gross Domestic Product) of regions and countries all over the globe versus their annual consumption of fuel. The data are from the International Energy Agency, Key World Energy Statistics, 2006. 

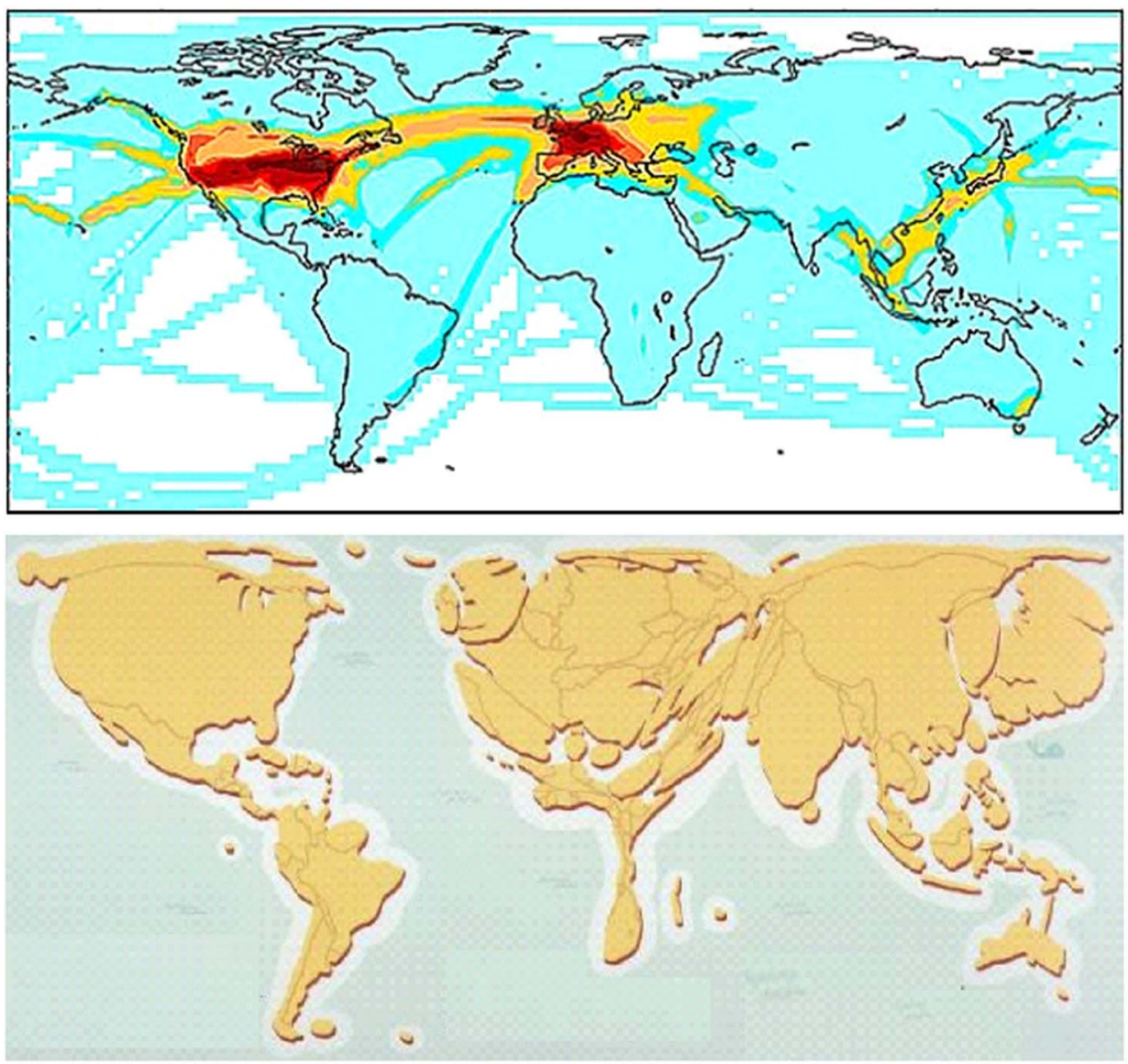

Figure 2. The world map of human air mass transit (where aircraft flew in 1992), ${ }^{6}$ and the distribution of wealth on the globe (countries have been enlarged or shrunk according to their GDP, cf. Figure 1).

cold on earth is movement: atmospheric and oceanic currents, biological flows, and human life.

All the needs of human life are reducible to this icon (Figure 3). The need to have heating (room temperature above the ambient temperature) requires the flow of heat from the fire to the ambient. The better we configure this heat flow, the more the heat passes through our living space before it is dumped into the ambient. The need to have air conditioning and refrigerated spaces is satisfied in the same manner: fuel is used to produce power, the power drives a refrigeration system that controls the temperature and humidity inside a building, in a hot climate. All the fuel is about facilitating human movement on the landscape, and about increasing the staying power of human life.

Completely analogous is the need to have water flowing through the living space. The construction of infrastructure for water delivery and removal requires work, 

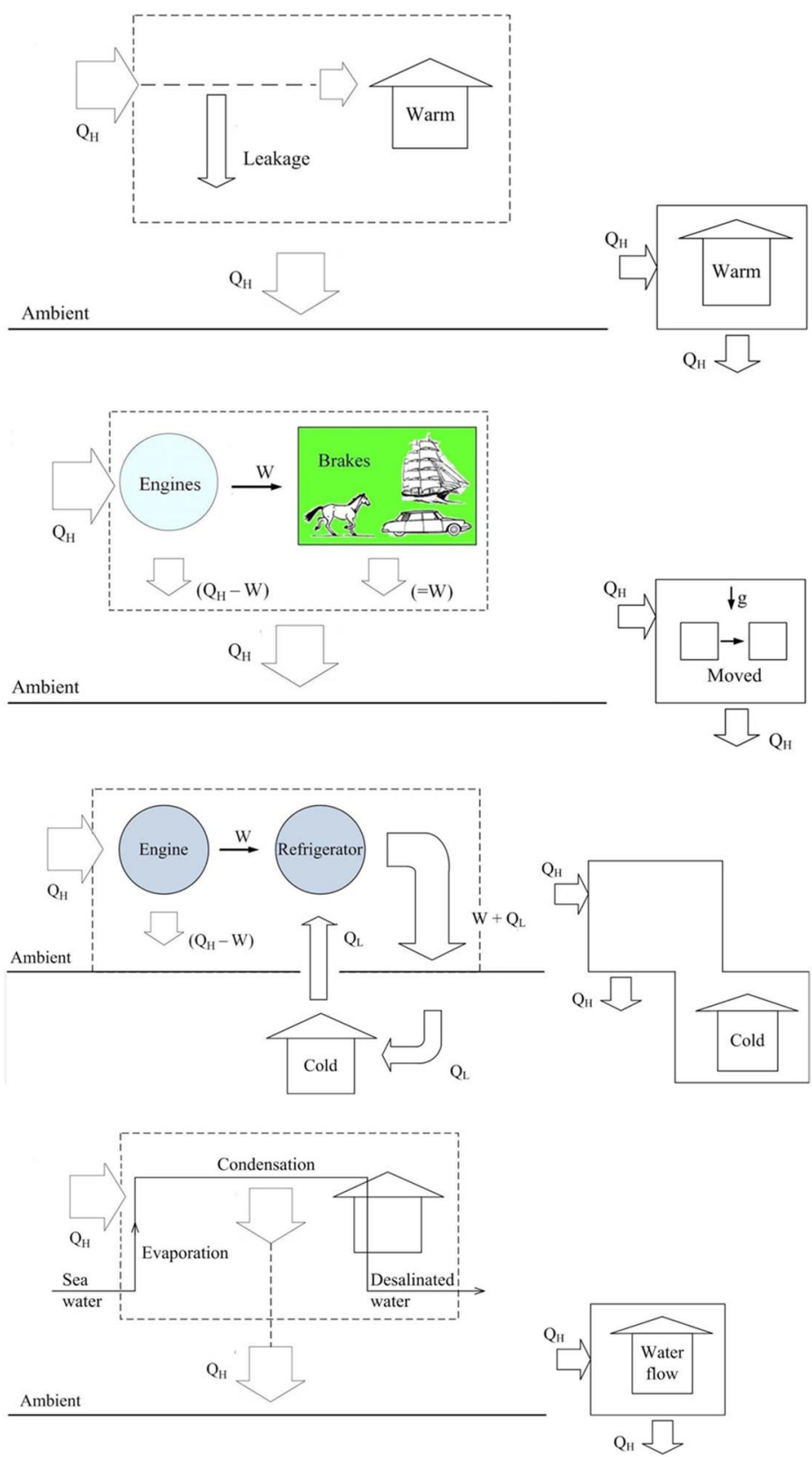

Figure 3. All the needs of humanity can be reduced to one flow: fuel is consumed, heat flows through the human space, from high temperature to ambient temperature, and the effect is beneficial for human life: heating, transportation, cooling, water, and the rest. 


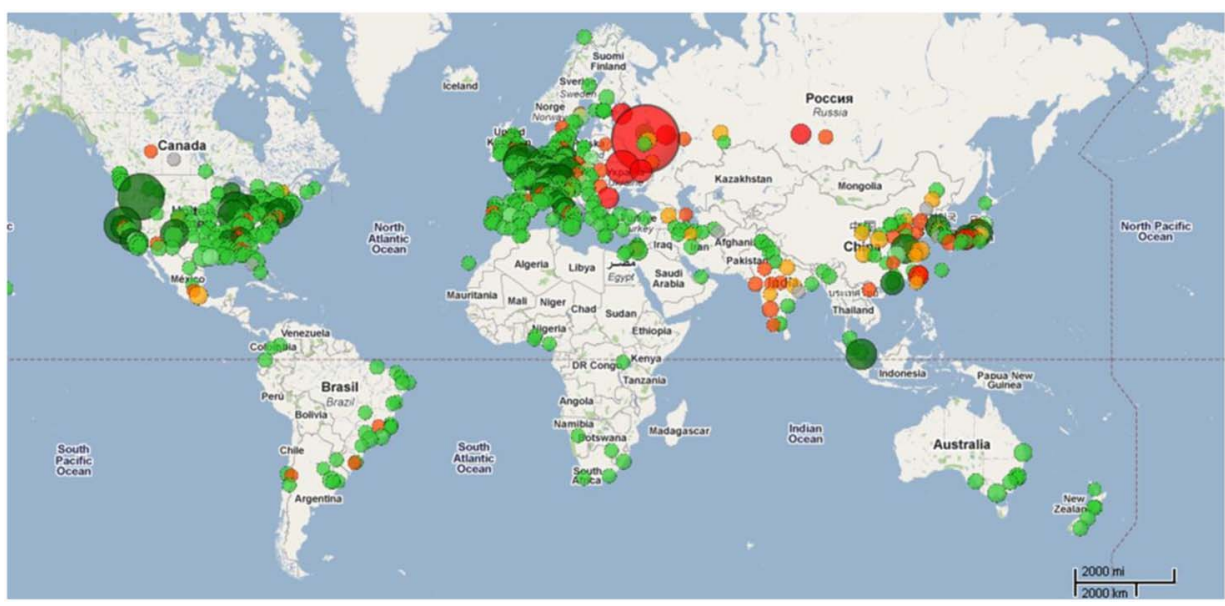

Figure 4. The world distribution of regions with highly cited scientific publications. $^{9}$

which comes from power plants that consume fuel. The need to have food (another stream of water that flows through the living space) is met through agriculture and irrigation, which require work constantly. In the arid regions of the globe the water supply comes largely from desalination. This too requires work from fuel.

Altogether, all the needs that define our modern living are streams driven by work or power. To facilitate and maintain these flows is the natural tendency that in physics (bio and non bio) is covered by the constructal law. ${ }^{2,3}$ In time, these streams swell as the society becomes more advanced, civilized and affluent. Better living conditions (food, water, heating, cooling) are achieved not only through the use of more fuel but also by better configuring the designs of all the things that flow and move. This activity of 'better configuring' is the evolution of science, technology, education, and communication.

We see this most clearly in the comparison of countries according to wealth (GDP) and fuel consumption (Figures 1 and 2). The world map of the generation of scientific ideas (Figure 4$)^{9}$ is essentially the same as the map of the distribution of human movement, wealth, and water use. Knowledge is the ability to change the organization (design) to facilitate the human flows. ${ }^{10}$ Knowledge spreads naturally because the tendency toward freely changing design to facilitate flow is universal.

The fuel that drives human flows is wealth (Figure 1), because it sustains the movement of people and goods, in accord with the tendency of all natural flow organizations to morph, to move more easily. The physical relation between fuel use, wealth and sustained movement is also responsible for the relation between wealth, life expectancy, happiness, and freedom (Figures 5-8). With the evolutionary principle that underpins these trends, biology and economics become like physics - law-based, exact, and predictable.

The burning of fuel and the resulting movement are not the only streams that represent wealth. There is also the creation of knowledge (science, education, information), technology and paths of communication. These morphing flow architectures happen because they are integral parts of the design of moving people 


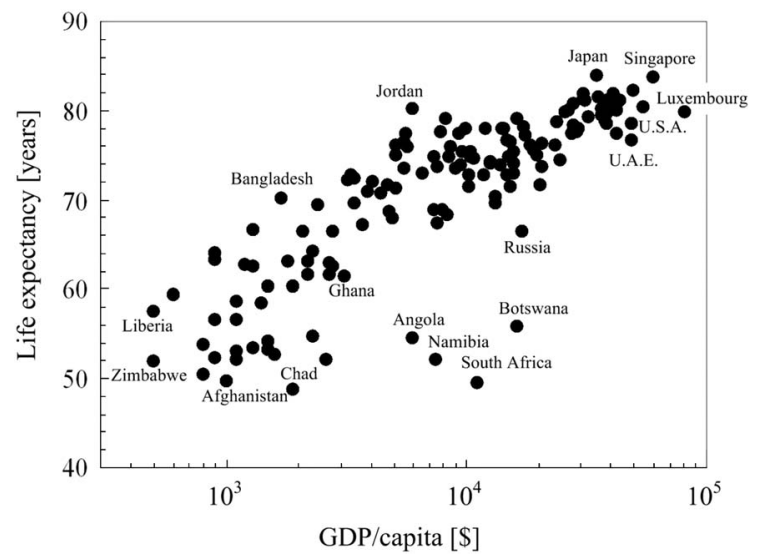

Figure 5. More economic activity also means longer life span (data from CIA World Factbook).

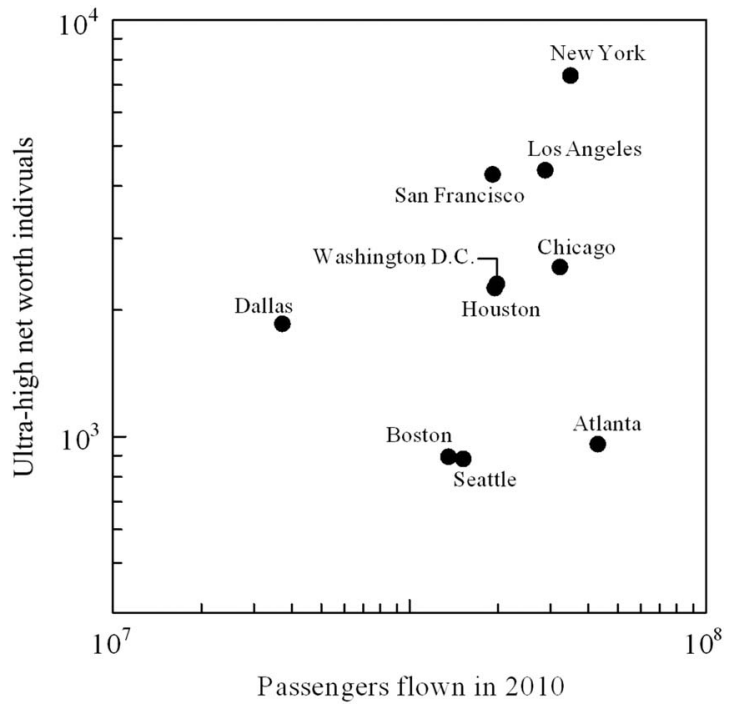

Figure 6. The rankings of cities according to air traffic and wealthiest inhabitants (data from Wealth-X and Bureau of Transportation Statistics, T-100 market).

and goods more effectively. They guide the process of changing and improving the design, to flow better. The flow of knowledge is an integral part of the material flow architecture on the globe, and it also means wealth - more, farther, more efficiently; all measurable in physics.

Seen through this physics lens the future is clear. It is a future of energy and water flow architectures, designs of channels where the few large and many small flow together. This future is here already. The movement of people and freight has evolved naturally into a tapestry of a few large roads and many small streets, and a few large 


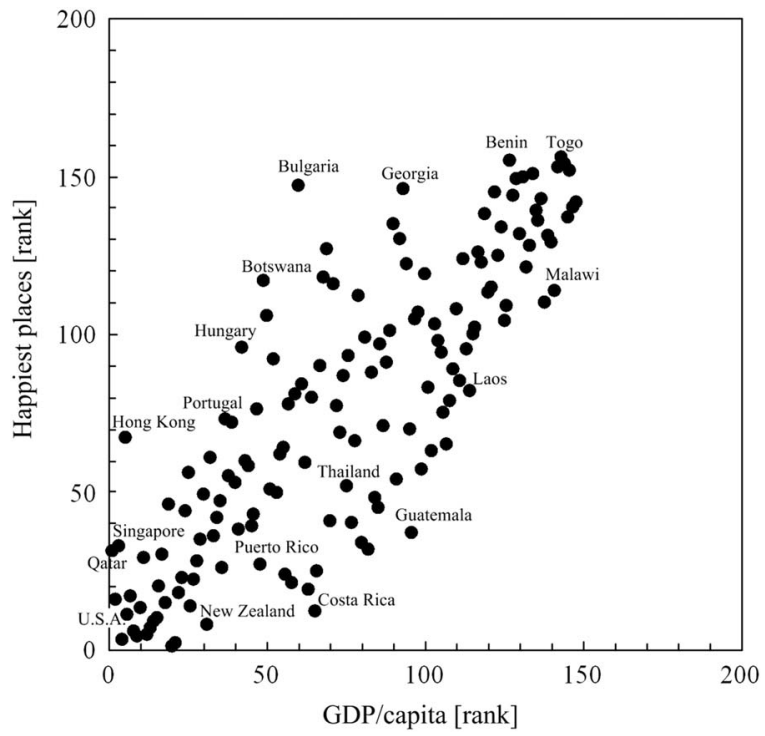

Figure 7. Movement (wealth) is broadly connected to 'happiness' (data from CIA World Factbook and World Happiness Report, Columbia University, 2012).

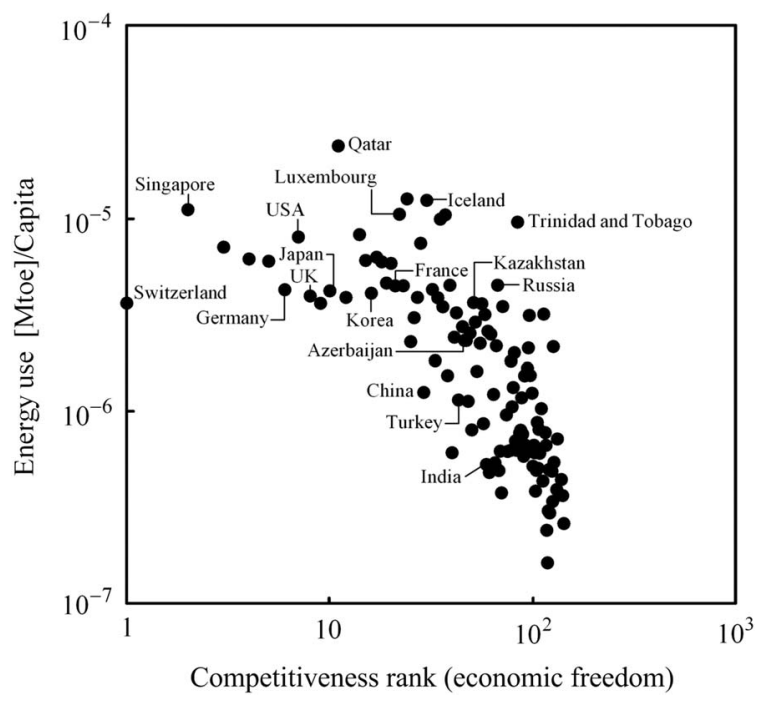

Figure 8. Free societies have wealth and staying power. Rigid societies have poverty and cataclysmic change. In time, all the countries are racing upward (cf. Figure 1), and this means that they are all evolving toward more freedom.

trucks and many small vehicles. In the animal kingdom, the few large and many small is the food chain.

This mental viewing reveals the designs that will empower the underdeveloped to move more, to have better roads, education, information, economics, peace and security. 
How is this to be done? By attaching the underdeveloped areas and groups better (with better flowing channels placed in better locations) to the trunks and big branches of the flow of economy on the globe. For these attachments to flow, the grand design needs the big rivers, the hierarchy. It needs the advanced. This is how to control the size of the gap between the developed and the underdeveloped, so that the whole design is efficient, stable and beneficial (healthy) to all its organs.

Distribution, allocation and the consumption of power and water should be considered together, as equal partners. This holistic view includes fields such as housing and transportation, building materials, heating and air conditioning, lighting, water distribution, etc. Taken together, all these concerns allow the global design to emerge with balance between the fuel streams that sustain human life on Earth.

Wealth is power, as physics: the power used to drive the currents that constitute the economic activity. The need to have water is the need to have power. They are manifestations of the greater need to have life (sustainability).

\section{References}

1. A. Bejan and J. P. Zane (2012) Design in Nature: How the Constructal Law Governs Evolution in Biology, Physics, Technology and Social Organization (New York: Doubleday).

2. A. Bejan and S. Lorente (2011) The constructal law and the evolution of design in nature. Physics of Life Reviews, $\mathbf{8}$, pp. 209-240.

3. T. Basak (2011) The law of life: the bridge between physics and biology. Physics of Life Reviews, 8, pp. 249-252.

4. A. H. Reis (2006) Constructal theory: from engineering to physics, and how flow systems develop shape and structure. Applied Mechanics Reviews, 59, pp. 269-282.

5. L. Chen (2012) Progress in study on constructal theory and its applications. Science China Technological Sciences, 55, pp. 802-820.

6. K. Gierens, R. Sausen and U. Schumann (1999) A diagnostic study of the global distribution of contrails, Part 2: Future air traffic scenarios. Theoretical and Applied Climatology, 63, pp. 1-9.

7. S. Ledu and S. Frattini (2009) Atlas des inégalités (Toulouse: Milan Jeunesse)

8. A. Bejan (2006) Advanced Engineering Thermodynamics, 3rd edn (Hoboken: Wiley).

9. L. Bornmann and L. Leydesdorff (2011) Which cities produce worldwide more excellent papers than can be expected? Journal of American Society for Information Science and Technology, 62, 1954-1962. http://arxiv.org/ftp/arxiv/ papers/1103/1103.3216.pdf

10. A. Bejan (2014) Maxwell's demons everywhere: evolving design as the arrow of time. Scientific Reports, 4, no. 4017, DOI: 10.1038/srep04017.

\section{About the Author}

Adrian Bejan is the J.A. Jones Distinguished Professor at Duke University, and is a member of Academia Europaea. He is a graduate of the Massachusetts Institute of Technology (BS 1971, MS 1972, PhD 1975). He has published widely on thermodynamics, evolutionary design, and the constructal law of organization in nature. 